\title{
Reconceptualising and Contextualising Sexual rights in the MENA Region: Beyond LGBTQI Categories
}

\author{
By Nasser-Eddin, Nof; Abu-Assab, Nour and Greatrick, Aydan
}

\section{Introduction}

In recent years, LGBTQI rights have become central to debates around international development, human rights, and diversity. As an organisation dedicated to promoting gender equality, women's rights, the rights of sexual minorities and marginalised groups including refugees and asylum seekers, with a focus on Arabic-speaking countries and people from the Middle East and North Africa (MENA), the Centre for Transnational Development and Collaboration (CTDC) has carried out four-year research into LGBTQI rights in the MENA region. Through this research, CTDC has identified major problems in policy and debate looking at LGBTQI lives in the region, and developed a tool to address such rights in programme development and advocacy. This tool favours the use of Sexual Practice and Gender Performance (SPGP) over SOGI rights, when doing work in the MENA region. The SPGP framework suggests that LGBTQI people and some non-normative heterosexuals face similar social, cultural and legal discriminations based on their nonnormative Sexual Practices and Gender Performances. The framework also suggests that people with non-normative sexualities and genders are not always necessarily self-identified LGBTQI individuals, and that LGBTQI identity categories are widely perceived by society as 'western' 'alien' and 'foreign' imports, and thus create backlashes against LGBTQI people. Piloting and further research has proven that the SPGP framework, on the other hand, is effective as it rallies non-LGBTQI people to seek changes in legal frameworks that affect all segments of the society, creating allies and bringing more people on board to advocate for freedom of sexual practice and gender performance. By utilising such a framework, development efforts will apply the 'leave no one behind' rule; in a more inclusive way that does not ineffectively just 'add-and-stir' different segments of the society blindly. The framework also ensures the implementation of the 'do no harm' principle, because it does not necessitate the 'outing' of self-identified LGBTQI people, in otherwise hostile contexts and environments. CTDC also believes that there is room for using this framework in refugee protection, resettlement and support programmes. Therefore, this article will argue that the SPGP framework is applicable to two types of work; one that seeks to advocate for the rights of self-identified LGBTQI people in Arabic-speaking countries, and an other that focuses on refugee protection and support mechanisms. To do so, we will first set the scene to demonstrate how discrimination against self-identified LGBTQI people is based on their sexual practices and gender performances that do not fit within society's mainstream expectations, and that for effective advocacy this needs to be addressed accurately. Later on, we move to demonstrate how refugee protection could benefit from a more inclusive approach and could meet their inclusion goals in a more meaningful way. 


\section{SPGP: The Framework}

Early in 2017, CTDC has published a comprehensive report under the title Contextualising Sexualities in the MENA region: Undoing LGBTQI Categories: Implications for Rights Based Advocacy Approaches. The report, on which this article is based, utilised qualitative and quantitative primary research methods such as interviews, focus groups and self-completion questionnaires, and secondary research methods including desk based literature reviews and social media monitoring. The report aimed to explore how people define their gender and sexuality in order to better inform policy and practice in the field of rights advocacy. It has become apparent that self-identified LGBTQI people face forms of persecution and discrimination that are very similar to those with non-normative genders and sexualities and do not identify as LGBTQI. This has led us to use the term non-normative to describe people who do not fit conventional gender roles and even norms, but are considered 'deviant' from the norms imposed by the society. The use of this term and of the SPGP framework has also been informed by a survey developed by CTDC and MOSAIC, and funded by Grindr for Equality, which gathered around 1,800 answers from men who have sex with men (MSMs) from all Arabic-speaking countries, in the MENA region and the Gulf, which showed that participants found it very difficult to fit themselves in a box and define themselves as LGBTQI. Interviews, focus groups, training workshops and other events organised by CTDC to non-normative people also highlighted the need for alternative terminology and methods to address gender and sexual rights that are relevant to the region, without pushing people to fit in a box or a category. This, however, cannot be done without exploring gender and sexuality in Arabic speaking countries, and this is, in this context, best done through an analysis of patriarchy and patriarchal gender roles.

We define patriarchy as a system of gender oppression that ascribes gender roles to both men and women, allowing no room for people with performances alternative to the 'man versus woman' binary system. This binary is imposed on men and women based on the sex they are assigned at birth. Those gender roles 'can be described as social norms, or rules and standards that dictate different interests, responsibilities, opportunities, limitations, and behaviours for men and women' (Johnson and Repta, 2012: 23). Based on that, men are expected to perform in masculine ways, and women are expected to perform in feminine ways. The masculine and the feminine are expressed in the way people dress, behave, speak and style their hair, etc. For long, development work has focused on women's issues or women's rights, overlooking those who perform their gender outside the binary system. The patriarchal gender order in Arabic-speaking countries also recognises 'men' and 'women' as the only gender identifications, considering any gender performance outside this 'norm' as unacceptable and in many cases can be persecuted. This binary system is in fact the starting point of discrimination against LGBTQI-identified people and people who have nonnormative gender performances and sexual practices.

Masculinity is a performance that is socially constructed and is expected to be performed by cisgender men, who were born male and identify as men. As a performance, however, nonnormative people, who are not male-born and/or not male identifying, can also perform masculinity. The same applies to femininity; it is socially expected that women will adopt feminine performances. However, as performances, masculinity and femininity can be performed by anyone outside the binary system. In our report, we argue that: 


\begin{abstract}
'Some people choose to perform masculine and feminine roles at the same time, and others choose to be gender queer, resisting such binaries. By looking at gender as a performance we are moving beyond gender as an identity category that is fixed and not changeable. This is of particular importance as the expectations for gender performances in fact vary across classes, cultures and nationalities. Specific behaviours that might be perceived as masculine in specific contexts might be deemed as feminine in others' (Abu-Assab, Nasser-Eddin and Greatrick, 2017: 11).
\end{abstract}

Our research has revealed that masculinity as a gender performance is praised and celebrated, whether men and/or women are performing it. In other words, if a selfidentified woman is perceived by society to be masculine, then her gender performance is celebrated. Hegemonic masculinity, characterised by strength, intelligence and independence, always commands more power in relation to the gender hierarchy vis-à-vis femininity (Connell, 2006). In other words, the practice and/or performance of masculinity are considered much more dominant than the performance of femininity. Having said that, this does not mean that gender performances are universal: there are other factors such as, class, age and race that intersect with gender, constituting a diverse range of experiences overall.

It has become apparent from our research that self-identified men who express feminine gender performances were more readily targeted than self-identified women who expressed masculine gender performances. Men who act in a 'feminine' way are seen and perceived by people in patriarchal conventional societies as 'downgrading' in their gender performances and thus performing a 'weaker' performance, or a performance that is perceived 'weak' in patriarchal societies. For example:

"I got hit twice in public just for being a bit feminine" (a self-identified gay man from Kuwait).

"I have been sexually abused multiple times and it happens to me because I look feminine, the abuser usually does not know anything about my sexual orientation, they do not know that I am bisexual, they assume I am gay just because I act in a 'feminine' way" (a self-identified bisexual man from Jordan).

"I was arrested by police on the way to a club for looking too feminine. I was tortured and humiliated for three days until one of my family members came and rescued me" (a self-identified transwoman in Egypt).

On the other hand, women who take on masculine gender performances are considered by the society as 'upgrading', and thus are far less targeted in patriarchal societies, because it is perceived as a 'better' performance. A woman who 'does' masculine roles is also labelled as 'Ukht Rjal' meaning literally the sister of men, meaning in this case that her gender 
performance is praised because she is taking on masculine roles. However, class plays a major role intersecting with gender and making women's experiences different. In other words, masculinities do not operate in the same way across classes. For example, a selfidentified queer woman from a working-class background in occupied Palestine said: "My parents, especially my father, encouraged my masculine behaviours. They perceived me as one of my other brothers, and they also thought that by acting in masculine ways I can protect the family's honour, and this means I would not engage in extramarital sexual encounters". Another self-identified queer woman from an upper-middle class family said "My mother always pushed me into the feminine. I was always a tomboy, but she always wanted me to sit in a 'proper' feminine way, with my legs closed, unlike men. She always hated my hair short, as she thought it made me look masculine".

Any gender performance that does not fit the norms is deemed to be 'deviant' in any society that follows the conventional gender (dis)order. Non-normative sexual practices are viewed as 'deviant' and 'abnormal' in those societies due to gender expectation as well. Homosexual relationships directly challenge the conventional gender order. There is an intersection between peoples' gender performances and the sexual practices they are expected to be engaged, or not, in. The connection between sexual practices and gender expectations is not enough discussed in development and/or in academic circles, and this connection is very important to draw particularly when we discuss gender and sexuality in Arabic-speaking countries. The patriarchal gender structure places control on peoples' sexual practices and preferences in the MENA region. Gender performances and sexual practices are persecuted and considered 'taboo', 'sins' and unacceptable in the MENA region, especially if they were visible, and because of the symbolic meaning of these practices and performances. For example, 'virginity' and 'honour' carry symbolic cultural meanings and the duty of 'preserving' them is assigned to women. Heterosexual women who have sex outside of marriage are considered outcast, because by being sexually active, they have contradicted what is culturally and socially expected from them. In many cases when women 'practise' sex outside of marriage, they are ostracised, and can be persecuted and criminalised, as they would be perceived as shaming the family's honour and reputation. Preserving the family's honour, which carries a symbolic cultural meaning, can entail anything, from women not being seen with men who are not related to them, and not losing their 'virginity' before marriage. Culture, class, age, and marital status, of course, can influence the degree of control over women's bodies.

On the other hand, non-normative people in homosexual relationships are often criminalised; when they are 'doing' a performance that can be 'seen' or that is 'visible'. For example, men, who visually present a feminine performance, and transwomen, are more likely to be suspected of as men who have sex with men, leading to their legal and social persecution. As for women who have sex with women, their sexual practice can be considered as less 'disturbing' to the patriarchal gender order, because a sexual encounter between women is thought of as not involving a phallus, and thus not involving clear penetration. Sex between men, on the other hand, is considered as more 'threatening' to the patriarchal structure, because it involves penetrative sex and a phallus is directly involved. 
In male homosexual relationships, the person who performs a 'dominant' and/or 'top' role is considered to be more masculine and thus stronger and their sexual practice is more in line with the role is expected from him by society. By contrast, the person who is at the 'receiving' end and/ or 'bottom' (i.e. the one who is penetrated) is seen to be 'effeminate', 'weak' and 'feminine' and therefore non-conforming to the performance expected of him. It has proven to be hard for MSMs because they are unable to meet social and cultural expectations and often find that they do not fit the stereotypes of what it means to be a 'man' and/or masculine (Nasser-Eddin, 2017). For example:

"I have never experienced anti-homo sexuality sentiments in Jordan because I look 'masculine' and 'manly', I would have had different experiences if I looked much more feminine, and that's why I never had a problem" (Self-identified gay man from Jordan).

"In this country when you're seen with a gay person, the community does not take it well. Even men who are feminine have to act like they're straight" (Self-identified gay man from United Arab Emirates).

It has become apparent from our research that MSMs whose gender performance does not fit the conventional gender order and men who are perceived as 'feminine' and 'passive' are the ones who are targeted and much more subjected to violence and harassment.

As for non-normative women, they talked more about the oppression they face because of their gender, and how gender intersects with other factors making their experiences much more different from that of men. Non-normative and self-identified LBT women often spoke about their gender, making gender more central to the conversation that sexual practice, as due to their gender they are expected to not engage in sexual activity outside marriage. In a focus group with non-normative women from the region, women talked about the multiple oppressions they face and how patriarchy influences their smallest life decisions. For instance, women were more likely to talk about control over their bodies, movement, dress and their careers, while this has not been the case for MSMs.

"Patriarchy is everywhere around. I am where I am because I am a woman. It is not because I am a lesbian. I cannot travel freely, and I cannot even imagine leaving my family's home to live with a partner. Patriarchy influences my relationships to everyone around me, including my mother, brother, and sister" (self-identified lesbian from Jordan)

"You know I do not think I am struggling because I am a lesbian. There is oppression and discrimination against women, even heterosexual women; you know they can go to prison just like us. Let's not forget also the political context, and who is running the country now, and how it is affecting personal freedoms" (self-identified lesbian from Tunisia).

This section aimed to demonstrate that persecution of self-identified LGBT people in Arabicspeaking countries is one that revolves around sexual practice and gender performance rather than an identity category. For this reason, we argue that advocacy efforts should also utilise this framework to better address the causes of discrimination, instead of using the SOGI (Sexual Orientation and Gender Identity) rights frameworks. 
We have established, so far, that people in the MENA region are persecuted and are subjected to violence and discrimination on the basis of their gender performance and sexual practice as acts, rather than identities. By looking at the situation through that lens, work on inclusion becomes mobilising rather than polarising. Through social media mentoring, we are able to identify trends in peoples' reaction to gender and sexual rights advocacy. It has become apparent, for example during the latest crackdown on selfidentified LGBTQI people in Egypt, that when the narrative revolved around rights based on SOGI, people reacted violently tearing apart social media campaigns and accusing people of treachery and forming western-alliances. On the other hand, when posts on social media focused on the fact that those in prison are being persecuted for being non-normative, looking unconventional, and not fitting within society's definition of masculinity and femininity, people posted positive comments and expressed support. SOGI-based rights advocacy has its limitations because it assumes an 'identity connection' that highlights the 'deviance', by focusing on self-identified LGBTQI people, singling them out and making them stand out. The term also imposes identity categories; for example, many people from Arabic-speaking countries who are attracted to the same sex do not feel that they fit within GBTQI categories. SPGP, on the other hand, allows room for alternative forms of nonnormativity, which are encompassing and inclusive.

We have tested the SPGP framework through workshops targeting families of self-identified LGBTQI people in Tunisia, and the results were very positive. Family members, who were not LGBTQI and/or non-normative, felt that they could identify with the experiences of nonnormative people, as at some point in their lives in a way or another they were subjected to restrictions over their freedoms. Freedom of gender performance in particular Sexual practice and gender performance freedoms were not controversial freedoms, through the framework families were able to understand that societal and legal restrictions should be challenged and addressed. Towards the end of the workshop, families were determined to draft a strategy to educate and advocate around gender and sexuality using SPGP, which they felt was more relevant to the MENA-context. In addition to advocacy, this tool is also useful in relation to refugee protection and support.

\section{Refugee Protection and Support}

Our field research and work with our partners in the MENA region has highlighted the important challenges facing many displaced peoples on grounds of their sexual practice and gender performance (Abu-Assab, Nasser-Eddin, and Greatrick 2017; Abu-Assab 2017; Greatrick 2017; Abu-Assab and Nasser-Eddin 2015). This spans from everyday persecution from host communities, employers, and fellow refugees, and also limitations in the response of international organisations and states in the Global North. Touching on personal accounts from partners, programme participants and practitioners, as well as qualitative research conducted by CTDC in Turkey, Lebanon, Jordan, Iraq and Tunisia between 2015-2017, we argue that support available to non-normative refugees is often too exclusive. Moreover, humanitarian work that seeks to single out non-normative peoples for protection, which are usually identified in humanitarian protection as LGBTQI, contributes to tensions within and between communities of non-normative peoples, host communities and refugees too, undermining the potential for broader collaboration between rights groups and the overall empowerment of communities in the region. CTDC engages with 
displacement as an important development issue, and not just a humanitarian one (Harild 2016), given that many refugees are increasingly trapped and immobile in transit countries for long periods of time (Fiddian-Qasmiyeh 2017). To this extent, it is important to reflect on LGBTQI asylum in key transit countries like Lebanon, Iraq, Jordan and Turkey as a shared development issue, that should target and support marginalised members of the host community too.

One of the key challenges facing non-normative refugees comes from the obligation to ' $\mathrm{fit}^{\text {' }}$ themselves into clearly defined LGBTQI categories in order to secure asylum. One refugee from Iraq, based in Berlin, reflected on how he needed to clearly demonstrate his 'gayness' in order to verify the veracity of his claim, often by playing up to gendered stereotypes of homosexuality (Abu-Assab, Nasser-Eddin, and Greatrick 2017: 18). This need to clearly demonstrate the 'credibility' (Millbank and Berg 2009; Millbank 2009) of an individual's identity is framed by the terms on which international protection is granted. Successful asylum applications are formed when the individual can clearly demonstrate 'a wellfounded fear of persecution owing to membership of a particular social group' (UNHCR 2012). The challenge here, however, is the relative vagueness of defining the social group (Webels 2011), often meaning decision makers are left to deduce from assumption or stereotype what it is that they expect to hear and see when it comes to LGBTQI asylum claims. These assumptions can be problematic, drawing on a normative understanding of sexual identity narratives and identities. This normative understanding can range from the assumption that lesbians should look 'butch' and gay men should look 'effeminate', to more embedded ideas about faith that assume you cannot be gay and also be a practising Muslim or Christian, for example. In this situation, the ability to secure protection often demands that the asylum seeker articulates themselves in straightforward ways: successful applicants will often 'speak the language of their rights' (Greatrick 2017), whilst unsuccessful individuals will be rejected as 'bogus' refugees (Jenicek, D. Wong, and Lee 2009) on grounds that they do not 'fit' into the assumptions of asylum officials and decision makers (Giametta 2017, 2014; Kivilcim 2017).

For non-normative people in the Middle East and North Africa, this need to 'fit' themselves into an LGBTQI category, what one practitioner in Istanbul described as developing an 'identity connection' (Greatrick 2017: 14) is particularly problematic in part because of the geographic and historically specific nature of LGBTQI categories:

"What matters is that [refugees] have a kind of identity awareness. Ok, I am gay, bisexual or transsexual. Somehow this makes it easier to find support. For other people, who might [...] not have an identity connection, they might not be able to access support. But of course, we have to ask whether or not this person is an LGBTI person or not" (a practitioner, Istanbul, 2016).

Feminist and queer scholars have highlighted how the equation of rights categories with identities obscures the subjectivity and 'inherent instability' (Spijkerboer 2015) of sexuality in favour of a number of tropes such as 'coming out' that demand sexuality is visibly performed and inscribed through a number of 'identity markers' such as speech, dress, mannerisms and so on. This places an onus on 'visibility', demanding that an individual's sexual practice is inscribed into a clearly visible and often gendered identity. This means 
that non-normative peoples must be seen in ways that are legible to asylum officials and practitioners, but must also live their sexual identities visibly, placing some in an impossible bind. As Zeynep Kivilcim has argued, sexual minority refugees in Turkey, who often hide their sexuality as a 'survival tactic', must simultaneously make their sexuality visible in order to access international protection and UNHCR's resettlement programme (Kivilcim 2017: 38).

In this way, adopting an SPGP approach as outlined above may encourage practitioners to 'resist the expectation that victims of sexual and gender identity based persecution should look, sound and be explicitly LGBTQI' (Abu-Assab, Nasser-Eddin, and Greatrick 2017: 16). This is particularly important when it comes to expanding the inclusivity of protection mechanisms. In terms of the protection that is offered, many practitioners rely on a logic that individuals who are not 'comfortable' to identify as LGBTQI do so because of 'internalised homophobia':

"[For] Turkish and English LGBTI people, it is easier to open the door and accept [the identities present in the support group], but for many [Arab refugees] with internalised homophobia there is a challenge to enter the room and deal with it. How can I deal with this? How can I deal with myself?" (A practitioner, Istanbul 2016).

This is particularly problematic for it demands innate sexual preferences and practices must be explained in relation to an awareness of one's position in the LGBTQI acronym - any reluctance to identify here is explained as a form of 'internalised homophobia', of being unable to come into a fixed identity because of some deep-rooted insecurity. However, the evidence many practitioners use to determine 'internalised homophobia' stem from language use, which is itself not evidence of a repressed or self-hating relationship with an individual's lutti sexuality. For example, Syrian refugees may refer to themselves as lutti. This is a common word that translates as 'faggot' and is sometimes used by Syrian refugees from rural areas to describe their own sexuality. However, this is sometimes seen as a derogatory word by practitioners, who interpret it as evidence of internalised homophobia. They instead encourage such individuals to describe themselves through the 'tolerant' and 'inclusive' language of LGBTQI rights adopted by international humanitarian and development organisations. This is despite the fact that, for many who may describe themselves as lutti, it is sometimes difficult to fit into the expectations of LGBTQI categories. In this way, work on sexuality can be class and culture-blind, asking marginalised peoples to describe themselves in very specific ways. As such, an assumed knowledge about sexual identities pervades the work of development and humanitarian actors, limiting the space for broader inclusion. However, as we suggest, moving away from a sole need to talk about sexuality through the lens of LGBTQI rights may encourage a more 'localised' discussion about sexuality. This does not require an individual to speak the language of LGBTQI rights in order to appear credible, but instead reflects on their own sexual subjectivity in ways that resonate with them and their particular experiences and background.

In navigating these different regimes of recognition, practitioners will often 'coach' nonnormative asylum seekers. This means that, in recognising the need to applicants to have an 'identity connection' in order to be successful in securing UNHCR resettlement, efforts will 
be taken to give refugees the language needed to pass the interviews, whilst leaving assumptions about what a refugee must sound and look like at the door:

"When I do the social assessment, I explain to the people that, after, in the later interviews they will ask you about these kinds of issues and that you have to give very specific responses to when you answer, because this is a process in UNHCR" (A practitioner, Beirut 2017).

CTDC's work on sexuality and gender reflects this approach: it is not enough to offer support to LGBTQI refugees, but to recognise these categories as a fairly narrow expression of experience. The key to good, inclusive work in both humanitarian contexts, however, is to build on them, and to work with those affected to develop a language and a safe space that does not expect individuals to identify in specific ways.

Rahul Rao has argued that the emphasis on visible, out and proud LGBTQI identities has helped to generate a 'homophobic counter discourse' that frames the particular idea of 'LGBTQI rights' (rather than sexuality or sexual practice) as part and parcel of a neocolonialist project (Rao 2012). In the context of the 'refugee crisis', this has seen homophobic groups and politicians in the Middle East mobilise against non-normative refugees and members of the host community on grounds that they do not belong in particular national groups. For example, in May 2016, President Erdogan criticised the EU for caring more about 'gays and animal rights' than Syrian refugees (The Guardian 2016), indirectly asserting the idea that LGBTQI rights had no place in Turkey which had, by his own reckoning, prioritised the needs of Syrians in general over the more 'frivolous' needs of sexual minorities. In Lebanon, this discourse also saw many organisations working to support the rights of non-normative asylum seekers directly attacked and criticised by groups like Hezbollah, who accused them of imposing Western values on Lebanese society. In both instances, groups opposed to LGBTQI rights have acquired political capital during the challenges of the 'refugee crisis'. Arguing that the needs of deserving Syrians in general, and economically dislocated members of Turkish and Lebanese host communities in particular, have been disregarded in favour of a Western concern for LGBTQI rights. The implications for both development and humanitarian work are stark, creating entrenched discourses around sexual rights that arguably destabilise the potential for long-term, sustainable empowerment of non-normative communities. This especially emerges when LGBTQI rights are used as the primary way of thinking about and responding to the needs of nonnormative peoples in the Middle East and North Africa. In this way, compartmentalising one's experiences to different identities and labels can single them out from their own community and further put them in vulnerable positions.

When it comes to the relationships between protracted non-normative refugees and their hosts, the SPGP approach is also important. Currently, the shared experiences of discrimination and persecution facing non-normative refugees and hosts in Lebanon, Jordan and Turkey are obscured by programmes that emphasise the vulnerability of refugees on the one hand, and attempts to empower host communities on the other. For example, humanitarian routes to protection, such as UNHCR resettlement, recognise the everyday forms of discrimination experienced by sexual minority refugees, such as limited access to livelihoods and routine homophobia from both fellow refugee communities and hosts, as 
grounds for asylum. Non-normative hosts, who are not able to access international protection, also share such challenges. This is particularly acute for trans individuals, who are denied many fundamental rights despite being citizens of their countries:

"But you know what, the real problem sometimes, for example, is that trans women from Lebanon cannot be refugees here in Lebanon and they cannot present themselves for travel. [...] they will tell you why can others [...] travel, and share their life, and for us we don't have this opportunity, for example. Some other services that are provided to refugees for free are not provided to Lebanese. This kind of issue sometimes causes some stress between the two communities" (A practitioner, Beirut 2017).

"There's some animosity from the Turkish LGBT community towards the Syrians in general, which also plays out towards the Syrian LGBT community" (a practitioner, Istanbul 2016).

This extends to other services too, such as sexual health support and access to free medication from providers. In such contexts, where everyday challenges between refugees and hosts are shared, the need to bring responses to the former into a broader conversation with programmes that seek to empower those with non-normative gender performances and gender practices more generally is vital.

Overall, our work with non-normative asylum seekers in Lebanon, Jordan and Turkey demonstrates the limits of LGBTQI categories in properly reflecting the breadth of experiences present in the region. The politics underpinning these categories are also generating, in the context of the 'refugee crisis', a backlash against 'illegitimate' sexual identities that can be more effectively navigated through the use of a language around gender and sexuality that is reflective of the local context, rather than just LGBTQI identity discourses. By applying the SPGP framework, which seeks to bring both the visible and the invisible nature of sexuality and gender into conversation with the intersections of class, gender, race, faith and nationality, we believe a more inclusive alternative to LGBTQI rights identities can be produced. In this way, our work on displacement encourages meaningful inclusivity by bringing "organisations and policy makers [into a] conversation with local and grassroots activists, and displaced peoples themselves' so that shared and particular experiences and identities are de-marginalised (Abu-Assab, Nasser-Eddin, and Greatrick 2017: 18).

\section{Conclusions and Recommendations}

This paper sought to present a newly emerging framework for work on gender and sexual rights that is more suitable to the context of the MENA region. The paper also sought to argue against the SOGI-rights and LGBTQI-rights frameworks, which are narrow in focus and can never guarantee the rights needed to improve the lives of self-identified LGBTQI people. The solution cannot be to 'add-and-stir' more groups to programming, but to build frameworks that are fundamentally inclusive from the beginning. However, this framework can remain ineffective without the backing of policy makers and funding bodies. It has become clear through this paper that non-normative people in the region are often 
persecuted due to their sexual practice or gender performance, rather than on the way they define themselves. In addition to that, the LGBTQI-rights framework is more divisive than inclusive, and instead of harnessing it leads to further division. Based on this article, and on CTDC's report, we suggest that practitioners and policy makers take the following recommendations into consideration:

- As genders and sexualities are performed and practised, development, advocacy and humanitarian frameworks addressing sexual and gender rights must take into consideration those who are marginalised by an LGBTQI or SOGI approaches.

- Inclusion must be addressed in an all-encompassing ways that guarantees that the needs of all those discriminated against due to their gender performance and sexual practice are tackled.

- Unifying efforts and using a unified language, between self-identified LGBTQI people and other non-normative people, helps in garnering social support, and is more likely to challenge discriminatory legal frameworks.

- There is a need to support personal rights and freedoms initiatives, and creating synergies between them and those advocating for gender and sexual rights in the region.

- 'Do no harm' and 'leave no one behind' are principles that should be strictly adhered to, when doing gender and sexual rights in the region, particularly because these issues are delicate and mistakes can lead to grave backlashes against non-normative people. Also, by leaving no one behind in the context of refuge we make sure that host communities are included and not polarised against the refugee community.

- To better address gender and sexual rights in the MENA region, there is a need to recognise the intersectionality between gender and sexuality, as well as class, religion, and nationality. Experiences in the MENA region are not homogenous, and recognising intersectionality helps to not only gain a better understanding, but also to respond to needs adequately.

\section{References}

- $\quad$ Abu-Assab, N. 2017. "Destabilising Gender Dynamics: Syria Post 2011." In A Gendered Approach to the Syrian Refugee Crisis, 16-25. London: Routledge. https://www.academia.edu/23431039/Destabilising Gender Dynamics Syria Post 2011.

- Abu-Assab, Nour, and Nasser-Eddin, N. 2015. "Syrian Refugees in Turkey: Gender Analysis." Centre for Transnational Development and Collaboration. http://ctdc.org/publication/syrian-refugees-in-turkey-gender-analysis/.

- $\quad$ Abu-Assab, N. Nasser-Eddin, N. and Greatrick. A. 2017. "Conceptualising Sexualities in the MENA Region: Undoing LGBTQI Categories." CTDC Publications. 
http://ctdc.org/publication/conceptualising-sexualities-mena-region-undoing-Igbtaicategories/.

- Connell, R. W. (2006) Masculinities (Polity, UK)

- Fiddian-Qasmiyeh, E. 2017. "Syrian Refugees in Turkey, Jordan and Lebanon Face an Uncertain 2017." The Conversation (blog). 2017. http://theconversation.com/syrianrefugees-in-turkey-jordan-and-lebanon-face-an-uncertain-2017-70747.

- Giametta, C. 2014. "'Rescued' Subjects: The Question of Religiosity for NonHeteronormative Asylum Seekers in the UK." Sexualities 17 (5-6):583-99. https://doi.org/10.1177/1363460714526130.

- - . 2017. The Sexual Politics of Asylum: Sexual Orientation and Gender Identity in the UK Asylum System. London: Routledge. https://www.routledge.com/The-Sexual-Politics-ofAsylum/Giametta/p/book/9781138674677.

- Greatrick, A. 2017. "Queer (Im)Mobilities and the 'Refugee Crisis': Examining Local Stakeholder Responses to Sexual Minority Refugees in Turkey." Working Paper, University College London. http://www.geog.ucl.ac.uk/research/researchcentres/migration-research-unit/workingpapers/MRU\%20WP\%20Aydan\%20Greatrick\%202017\%201.pdf/view.

- Harild, N. 2016. "Forced Displacement: A Development Issue with Humanitarian Elements | Forced Migration Review." Forced Migration Review 52:4-7.

- Jenicek, A,; Alan D. Wong, and Edward L. 2009. "Dangerous Shortcuts: Representations of Sexual Minority Refugees in the Post-9/11 Canadian Press." Canadian Journal of Communication 34 (December). https://doi.org/10.22230/cjc.2009v34n4a2119.

- $\quad$ - Johnson, J. and Repta, R. (2012) "Sex and Gender: Beyond the Binaries" in Oliffe, J. and Greaves, L. (eds.) Designing and Conducting Gender, Sex, and Health Research (Sage Publications, UK)

- Kivilcim, Z. 2017. "Lesbian, Gay, Bisexual and Transsexual (LGBT) Syrian Refugees in Turkey." In A Gendered Approach to the Syrian Refugee Crisis, 26-40. London: Routledge. https://www.academia.edu/23431039/Destabilising Gender Dynamics Syria Post 2011.

- Millbank, J. 2009. "From Discretion to Disbelief: Recent Trends in Refugee Determinations on the Basis of Sexual Orientation in Australia and the United Kingdom." The International Journal of Human Rights 13 (2-3):391-414. https://doi.org/10.1080/13642980902758218.

- Millbank, J, and Laurie Berg. 2009. "Constructing the Personal Narratives of Lesbian, Gay and Bisexual Asylum Claimants." International Journal of Human Rights 13 (2/3). https://papers.ssrn.com/abstract=1339581.

- Nasser-Eddin, N. (2017) Gender Performativity in Diaspora: Syrian Refugee Women in the UK in Freeman, J, Kivilcim, Z. and Ozgur Baklacioglu, N. (eds.) A Gendered Approach to the Syrian Refugee Crisis. Routledge Publishers: London.

- $\quad$ Rao, R. 2012. Third World Protest: Between Home And The World. Reprint edition. Oxford: Oxford University Press, Usa.

- Spijkerboer, T. ed. 2015. Fleeing Homophobia. 1 edition. London: Routledge.

- The Guardian. 2016. "Erdoğan Says West Cares More about Gay and Animal Rights than Syria | World News | The Guardian," May 13, 2016. 
https://www.theguardian.com/world/2016/may/13/erdogan-says-west-cares-moreabout-gay-and-animal-rights-than-syria.

- UNHCR. 2012. "Guidelines on International Protection No. 9: Claims to Refugee Status Based on Sexual Orientation and/or Gender Identity within the Context of Article $1 \mathrm{~A}(2)$ of the 1951 Convention and/or Its 1967 Protocol Relating to the Status of Refugees." UNHCR. http://www.unhcr.org/50ae466f9.pdf.

- Webels, J. 2011. "Sexual Orientation in Refugee Status Determination." University of Oxford. https://www.rsc.ox.ac.uk/files/files-1/wp74-sexual-orientation-refugeestatus-determination-2011.pdf. 